\title{
"UNA CIUDAD \\ PARTICIPATIVA Y EFICAZ. DERECHO A UN ESTADO MUNICIPAL TRANSPARENTE Y CERCANO A LA GENTE"
}

\author{
de Mónica Bifarello (2005)
}

en Experiencia Rosario (más ciudad / más humana). Ed. Logos, Rosario, pp. 63-124.

por Pablo Gorbán

Este artículo forma parte del libro que recoge la experiencia de políticas públicas aplicadas en Rosario en la última década que fuera editado con motivo de La Feria de Gobernabilidad realizada en dicha ciudad, en el marco de la distinción otorgada por el Programa de las Naciones Unidas para el Desarrollo por los logros obtenidos en materia de desarrollo social.

Una de las características más significativas del documento que nos ocupa es la visión renovada que ofrece de la gestión pública. En los últimos años, el concepto de "democracia representativa" se ha ido transformando, desarrollándose instrumentos que ayudan a hacer de ella una democracia también participativa, que plantea nuevas formas de articulación entre la sociedad civil y el Estado en la búsqueda de fortalecimiento del sistema democrático.

En este contexto, el gobierno local debe jugar un papel importante como "agente de desarrollo estratégico" que impulse y trabaje para la "construcción de ciudadanía", un concepto que es clave en la formulación de políticas públicas y el cual va dejando entrever su significado a medida que transcurre el ensayo.

Esa relación entre Estado y sociedad civil, que evoluciona y se transforma desde la gestión, se encuentra tanto explícita como subyacente lo largo de la obra. Es causa y consecuencia de las políticas aplicadas y es el eje central a partir del cual se encaran la transformación y el rediseño del Estado local.

La estructura del documento presenta tres secciones diferentes pero relacionadas. La primera hace referencia al proceso de planificación estratégica desarrollado en la ciudad. La segunda describe el proceso de reforma de la gestión local en relación con la descentralización. Y la tercera destaca el rol jugado por la participación ciudadana en la 
reconstrucción de la esfera pública.

En la primera sección se detalla el proceso de implementación del Plan Estratégico y sus consecuencias en torno a la calidad de la interacción del gobierno con las organizaciones empresariales y con la sociedad civil. Aquí, la gestión pública se nutre de este vínculo para transformarse en abierta, flexible y participativa, a la vez que expresa esta nueva fisonomía en una relación con la ciudadanía más institucional que directa.

En la segunda sección se destaca el proceso de descentralización en el marco de la modernización municipal. Más allá de la tecnología digital, el proceso requiere nuevas tecnologías de gestión que permitan alcanzar los objetivos de eficacia en la prestación de senvicios y participación de los vecinos en la iniciativa. Para esto se trabaja en tres aspectos básicos de la descentralización: el operativo, el administrativo y el político, los cuales se materializan territorialmente en seis distritos municipales. En todo esto se observa un claro intento de acercar la gestión al ciudadano, de simplificar y agilizar los procesos.

En la tercera sección se hace una revisión del recorrido de Rosario en materia de participación. Por un lado, se discuten las distintas formas y matices de la misma, destacando las experiencias a escala de barrio, de distrito y de ciudad. Por otro, se centra la atención en una experiencia clave, como es el Presupuesto Participativo; y en la búsqueda de un modelo de cogestión esta herramienta permitiría acercarse hacia los objetivos de participación, democracia y transparencia.

Estos temas ilustran el tono general del artículo, descriptivo pero a la vez crítico. Cualquier reforma puede fracasar si no está bien determinada su orientación política. Se deben tener claros el horizonte de acción y la visión de la ciudad que se pretende como condición previa de la aplicación o puesta en marcha de estos procesos. En este sentido, esta obra proporciona una aproximación muy interesante en lo que respecta a las vinculaciones entre la política, las modalidades de gestión y la participación de la ciudadanía en los procesos de gobierno.

El informe, si bien adolece de detalles en cuanto a la búsqueda de consensos y al grado de cohesión social necesario para avanzar en la reforma, además de un aporte a la difusión de la experiencia Rosario, constituye una lectura altamente recomendable para todos aquellos que, desde el sector público, intentan, a través de la gestión, avanzar hacia un modelo de democracia que genere las condiciones para una nueva relación entre Estado y sociedad civil. 